\title{
PROTECCIÓN DE LOS DERECHOS ADQUIRIDOS, CIERTOS E INDISCUTIBLES DE LOS TRABAJADORES DE SINCELEJO, DURANTE EL AÑO 2017
}

\author{
Sandra Elena Anaya Sierra ${ }^{1}$
}

\section{Resumen}

El presente capitulo desarrollo los fundamentos teóricos y jurídicos de los derechos adquiridos, ciertos e indiscutibles de los trabajadores, los instrumentos para dar protección a dichos derechos, sumado a un análisis estadístico prestado por Consultorio Jurídico de la Corporación Universitaria del Caribe CECAR, en el área de Derecho Laboral, durante el año 2017, tomando en cuenta que en nuestro medio, generalmente, las personas humildes y vulnerables concurren al Consultorio Jurídico de CECAR en busca de una asesoría jurídico laboral, por considerar la vulneración flagrantemente de sus Derechos Laborales los cuales emanan de un contrato de trabajo, sea verbal o escrito, brindándoles la asesoría solicitada dentro del contexto jurídico vigente. Con el presente estudio se logró establecer que el aporte es significativo en asesoría y/o acompañamiento jurídico de protección de los derechos adquiridos, ciertos e indiscutibles, predominando la presentación, seguimiento y finalización de Demandas Ordinarias Laborales de Única Instancia, ante Juez de Pequeñas causas laborales.

Palabras clave: Derecho al trabajo, Derecho de igualdad, derechos adquiridos, ciertos e indiscutibles y trabajadores.

$1 \quad$ Candidata a Magister, Especialista en Derecho Laboral y en Derecho Administrativo, Abogada. Docente de la Facultad de Derecho de la Corporación Universitaria del Caribe. Adscrita al Centro de investigación Socio jurídicas de la Corporación Universitaria del Caribe GISCER. Email: sandra.anaya@cecar.edu.co 


\section{Abstract}

This chapter develops the theoretical and legal foundations of the acquired rights, certain and indisputable of the workers, the instruments to give protection to those rights, added to a statistical analysis provided by the Legal Clinic of the Corporation Universitaria del Caribe CECAR, in the area of Labor Law, during the year 2017, taking into account that in our environment, generally, the humble and vulnerable people come to CECAR's Legal Office in search of legal labor advice, considering the flagrant violation of their Labor Rights which emanate from an employment contract, whether verbal or written, providing the advice requested within the current legal context. With the present study it was possible to establish that the contribution is significant in advising and/or legal accompaniment of protection of the acquired rights, certain and indisputable, predominating the presentation, follow-up and finalization of Ordinary Labor Claims of Only Instance, before Judge of Small labor cases.

Keywords: Right to work, Right to equality, acquired rights, certain and indisputable rights and workers.

\section{Introducción}

El trabajo como un derecho fundamental, se encuentra ampliamente protegido por la Ley, la jurisprudencia, la doctrina y los convenios de la Organización Internacional del Trabajo ratificados por Colombia concebido en un Estado Social de Derecho, de igual forma el Estado es el encargado de dar protección al trabajo en condiciones dignas y justas.

Los consultorios jurídico área laboral presta asesoría jurídica gratuita a usuarios que requieren el servicio por ellos es importante saber ¿cuáles es el aporte jurídico de CECAR a la protección de los derechos adquiridos, ciertos e indiscutibles de los trabajadores en Sincelejo Sucre año 2017, ante este interrogante y en aras de darle respuesta se identificarán los fundamentos teóricos de los derechos adquiridos, ciertos e indiscutibles de los trabajadores en Colombia y de los instrumentos jurídicos mediante los cuales se da protección a estos Derechos en el ordenamiento jurídico colombiano, teniendo en cuenta un análisis estadístico de consultorio jurídico de CECAR en materia laboral año 2017. 


\section{Metodología}

Para el desarrollo de la investigación se planteó un diseño metodológico estructurado en el paradigma de la investigación cualitativo, apoyado en el enfoque hermenéutico, e implementando en momentos justificados los tipos de investigación exploratorio, descriptivo y correlacional, de acuerdo a la estrategia trazada. Como indica Palencia (Palencia, 2009) el enfoque es cualitativo, puesto que la investigación se orienta a abordar el objeto de estudio a partir de las cualidades que lo definen y caracterizan, desde los hechos, procesos y estructuras. Todo a partir de una revisión literaria constante y un proceso de hermenéutico de las instituciones y seres vivos relacionados con el tema de estudio. Las técnicas de información son la lectura del material bibliográfico y análisis de la información. La investigación es de tipo cualitativa porque se pretende describir cuales han sido los Aportes del Consultorio Jurídico de CECAR a la protección de los derechos adquiridos, ciertos e indiscutibles de los trabajadores de Sincelejo durante el año 2017, La investigación cualitativa es un multimétodo focalizado, incluyendo interpretación y aproximaciones naturalistas a su objeto de estudio (Denzin, 2012) , es por esta razón que basados en la experiencia diaria en la atención de trabajadores de escasos recursos, se documenta el efectivo aporte del consultorio jurídico en la protección de derechos laborales.

Por otro parte, esta investigación es de naturaleza jurídica con un enfoque epistemológico. Es jurídica por cuanto las fuentes principales objeto de análisis son normatividades que rigen los derechos ciertos e indiscutibles de los trabajadores y de la competencia establecida por mandato legal que tiene el consultorio jurídico como centro de prácticas jurídicas y de proyección social para garantizar la protección de dichos derechos, además, tiene un enfoque epistemológico porque se realizará un análisis estadístico que se interpretará y describirá a lo largo del desarrollo de la presente investigación, a partir de datos existentes en el archivo de las monitorias de consultas y trámites procesales del consultorio jurídico. De igual forma se destaca el cumplimiento por fases de los objetivos como los son la identificación de los fundamentos teóricos de los Derechos adquiridos ciertos e indiscutibles de los trabajadores en Sincelejo, identificación de los instrumentos jurídicos que los respaldan y el análisis estadístico de Consultorio Jurídico CECAR en materia laboral 2017 contribuyendo con la respuesta de la pregunta problema que nos ocupa. 


\section{Fundamentos teóricos y jurídicos de los Derechos Adquiridos, Ciertos e indiscutibles de los trabajadores en Colombia.}

La explotación de los indígenas en nuestro territorio, por parte de los conquistadores movió a los monarcas españoles promulgar a algunos ordenamientos tendientes a proteger la condición humana de los aborígenes. Esas normas a pesar de no haber suministrado alivio completo a sus penurias fueron el origen de nuestra legislación laboral. Posteriormente el expresidente José Hilario López, abolió la esclavitud en nuestro país a partir del 1 de enero de 1852, marcando una nueva era en los derechos laborales. Más tarde fueron apareciendo los primeros conflictos laborales a los cuales se les trataba de dar solución mediante la aplicación de normas contempladas en el Código Civil, pero existían situaciones concretas que no tenían regulación alguna en el mencionado código y comienzan entonces a surgir las primeras leyes sociales que tratan de dar solución a esos conflictos hasta llegar a la expedición de nuestro Código Laboral Colombiano, el cual que ha tenido algunas modificaciones, regulando de esta manera las relaciones individuales, colectivas de trabajo, la seguridad social y procesal laboral.

No obstante, en aras de identificar el origen del derecho laboral en Colombia Se ha logrado establecer como origen del derecho del trabajo contemporáneo la división de clases que surgió a causa del nacimiento y el auge del capitalismo de la tesis individualista sobre la libertad, y específicamente respecto de la libertad en el terreno económico. La aparición en la vida política y social y comercial de los pueblos, sobre todo en Europa, de una clase burguesa que apoyada en la tesis de la libertad económica irrestricta, tomó para así, no solo los dos instrumentos de mando sino los bienes y elementos de la producciónexpresión inequívoca del derecho de propiedad privada fue creando de contragolpe una vista de clase social desposeída no solo de tales bienes , sino de la posibilidad de obtenerlas y reducida por pugna de los hechos económicos a la necesidad de comprometer su fuerza de trabajo para subsistir. Esta clase es el proletariado, y se forma, se levanta y progresa en un ambiente de franca hostilidad hacia las clases económicas fuertes, las que, de su parte, poco repararon en el fenómeno social político y humano que se avecinaba, empeñadas, como se encontraban de manera exclusiva, en el proceso de explotación económica y de atesoramiento de riquezas, por todo los medios lícitos e ilícitos. (Gonzalez Charry Guillerom , 2016) 
El proceso de crecimiento de proletariado, su distanciamiento de las altas clases y, por lo tanto, de los gobiernos que son expresiones de aquellas, toma inesperado impulso con el auge de las grandes industrias y con la aparición en la historia de la época llamada capitalismo industrial. La demanda cada vez mayor de mano de obra a medida que aumentaba el número de empresas y el poder industrial de ellas, el abandono de los campos por los trabajadores, atraídos por la posibilidad de mejor salario y alagados por posibles comodidades materiales, va haciendo que aquellas masas adquiera dimensiones gigantescas, aunque desordenadas al principio, tanto desde el punto de vista disciplinario y doctrinario, como el desamparo e indiferencia oficial. (Gonzalez Charry Guillerom , 2016).

Derecho laboral constituye un conjunto de normas y principios que regulan las relaciones individuales y colectivas que se presentan entre empleadores y trabajadores, el Derecho laboral individual constituye una pequeña parte del Derecho Laboral conformada por un conjunto de Derecho y obligaciones de las partes empleador trabajador, protegido este vínculo laboral por normas plasmadas en la Constitución Política, el Código Laboral, los convenios internacionales adoptados por Colombia y demás normas protectoras de los Derechos que nacen en el vínculo laboral, a su vez estos Derechos mirándolos desde el punto de vista del trabajador son Derechos Adquiridos, ciertos e indiscutibles, son adquiridos porque forman parte del patrimonio del trabajador, ciertos e indiscutibles porque son de consagración legal, por lo tanto las disposiciones legales que regulan el trabajo humano son de orden público y, por consiguiente, los derechos y prerrogativas que ellas concedan son irrenunciables (Derecho Laboral Colombiano relaciones individuales, 2014) Ejemplo: X, trabajador, vinculado a una empresa mediante un contrato de trabajo, laboró un mes. Al mes tiene derecho al pago del salario pactado constituyen así su Derecho adquirido, cierto e indiscutible no admite ninguna duda ni tampoco es una mera expectativa, se puede conciliar.

Entendemos por contrato de trabajo un negocio jurídico bilateral libremente adoptado entre trabajador y empresario, por medio del cual se constituye una relación jurídica obligacional entre ambas partes, caracterizándose este contrato por ser nominado, sinalagmático, oneroso, consensual, intuito persone, de tracto sucesivo, normado, entre otras características (Cruz, J, 2017). Podríamos afirmar que los Derechos adquiridos, cierto e indiscutibles de un trabajador nacen desde el momento en que se constituyen los tres elementos esenciales de un 
contrato de trabajo que son la subordinación, prestación personal del servicio y salario de igual manera las modalidades de contrato de trabajo más utilizadas son a término fijo y a término indefinido Verbal.

La subordinación se manifiesta en el hecho de que el trabajador pone a disposición del empleador su fuerza de trabajo de modo que la prestación personal del servicio está sometida a los poderes organizativos y de dirección del empresario y que a cambio paga una retribución por servicio prestado denominada salario, pero si se trata de derechos inciertos y discutibles siendo estos los que generan duda porque lo constituyen hechos que admiten muchas interpretaciones, hechos que son imprecisos y/o hechos que están supeditados al cumplimiento de alguna circunstancia de su nacimiento, entonces estos no gozan de beneficios propios de los derechos adquiridos ciertos e indiscutibles y permiten por consagración legal la figura jurídica de la transacción definiéndose esta como un contrato por medio del cual las partes contraen voluntariamente obligaciones específicas, se refiere a acuerdos privados sin intervención de funcionarios públicos. (Figueroa, 2016)

A lo largo de los tiempos ha sido difícil para la doctrina tratar de dar una caracterización o teoría del concepto de Derecho adquirido cierto e indiscutible, lo han mirado desde diferentes aspectos, por ejemplo: Los hermanos Mazeund (Barona, 2010, pág. 262) encuentran justificada la diferenciación hecha por la doctrina clásica entre derecho adquirido y expectativa. Para ellos, es derecho adquirido aquél "que ha entrado definitivamente en un patrimonio, o una situación jurídica creada definitivamente" y, expectativa, "es una esperanza no realizada todavía". Para Louis (Barona, 2010, pág. 262), entre sus apartes se encuentra que "los derechos adquiridos deben ser protegidos, incluso contra una ley nueva: ésta no podría privar de un derecho a las personas que están definitivamente investidas del mismo, a la inversa, las simples expectativas ceden ante la ley nueva, que puede atentar contra ellas y dejarlas sin efecto", y consideran que "la necesidad de seguridad está suficientemente garantizada si el derecho adquirido está amparado, y las simples expectativas deben ceder ante una ley que se supone más justa". (Gerencie.com) En el libro Lecciones de Derecho Civil (Barona, 2010) define los derechos adquiridos como los que forman parte de nuestro patrimonio y que no lo pueden desaparecer. Por otra parte, Bonnecase (Barona, 2010, pág. 262) considera que la noción clásica del derecho adquirido debe sustituirse por la de "situación jurídica concreta" y a su turno, la noción de expectativa debe ceder el puesto a la de 
"situación jurídica abstracta". Fiore (Gerencie.com, 2010)define el derecho adquirido como "el derecho que alude de perfección el idóneo. Gabba (Gerencie.com, 2010) sostiene que "es adquirido todo derecho que entra inmediatamente a formar parte del patrimonio de quien lo ha adquirido, la consecuencia de un acto idóneo y susceptible de producirlo, en virtud de la ley del tiempo en que el hecho hubiere tenido lugar, aunque la ocasión de hacerlo valer no se presentase antes de la publicación de una ley nueva relativa al mismo, y por los términos de la ley bajo cuyo imperio se llevará a cabo". Julián Restrepo Hernández, tratadista colombiano, considera que "los derechos adquiridos son pues las consecuencias jurídicas nacidas en virtud de una ley vigente al cumplimiento del hecho previsto en la misma ley". Jurídicamente son protegidos, estos derechos por la Constitución Política en especial los siguientes artículos 3,7.8.9.10,11,13,19,21,22,23 ,37,38,39, 46,47, 53,58,48, 64,65, 90,91, entre otros. El articulo 53 C.P. (Constitución Politica Colombiana, 1991) Preceptúa El Congreso expedirá el estatuto del trabajo. La ley correspondiente tendrá en cuenta por lo menos los siguientes principios mínimos fundamentales:

Igualdad de oportunidades para los trabajadores; remuneración mínima vital y móvil, proporcional a la cantidad y calidad de trabajo; estabilidad en el empleo; irrenunciabilidad a los beneficios mínimos establecidos en normas laborales; facultades para transigir y conciliar sobre derechos inciertos y discutibles; situación más favorable al trabajador en caso de duda en la aplicación e interpretación de las fuentes formales de derecho; primacía de la realidad sobre formalidades establecidas por los sujetos de las relaciones laborales; garantía a la seguridad social, la capacitación, el adiestramiento y el descanso necesario; protección especial a la mujer, a la maternidad y al trabajador menor de edad. (constituciion politica de colombia, 1991)

Constituye la anterior disposición constitucional un amparo a los derechos adquiridos, ciertos e indiscutibles de los trabajadores al establecer un mínimo de derechos y garantías consagrados a favor de los trabajadores.

De igual manera en aras de dar una explicación podría aseverar que nuestro Código Laboral Colombiano en la parte individual, que nos ocupa, es un reconocimiento a los Derechos adquiridos, ciertos e indiscutibles de los trabajadores Ejemplo Art 10 Igualdad, Art 11 Derecho al trabajo, Art 13 Mínimo de derechos y garantías, Art 19 normas de aplicación supletoria, Art 21 Principio de favorabilidad, Art 22 y 23 Contrato de trabajo y elemento, Art 46 Contrato de trabajo a 
término fijo, Art 47 Contrato de trabajo a término indefinido Art 249 Auxilio de cesantías, Art 186 Vacaciones, Art 230 y S.S Dotación, Art 306 Prima de servicios, Art 64 Indemnización por despido injustificado, 65 indemnización por falta de pago. Art salario, Art 86 periodo de prueba, Art 127 salario y demás normas, de igual forma las leyes que entran a regular ciertos aspectos importantes como la Ley 789 de 2002, la Ley 50 de 1990, Ley 100 1993, Ley 52 de 1975, Ley 27 de 1982 etc.

De otro lado la jurisprudencia ha tratado de dar un cimiento jurídico y/o a poyo a los derechos adquiridos ciertos e indiscutibles de los trabajadores en innumerables jurisprudencias ejemplo C.177 de 2005, C 168- 1995, C- 663 de 2007, C 1772005 (Corte Constitucional Colombiana) entre otras. Las tesis jurisprudenciales y doctrinales en el tema de los derechos adquiridos, ciertos e indiscutibles que nos ocupa en Colombia se ha caracterizado por las siguientes precisiones: Establecen estos derechos como intangibles involucrados en el patrimonio del trabajador los cuales no puedes ser desconocidos, caracterizados por ser de orden público e irrenunciable, jamás constituyen una mera expectativa por cuanto están reconocidos por la Ley y no pueden modificarse por mera iniciativa, constituyen sinónimo de justicia y de equidad, están cubierto de protección legal que le impiden su desconocimiento por parte de quien ejerce la subordinación, constituyen todas aquellas situaciones individuales y subjetivas creadas y definidas por la Ley, son situaciones jurídicas consolidadas y el legislador no puede expedir leyes que los desconozca o vulnere.

De otro lado los convenios y/o recomendaciones dela O.I.T organización internacional del trabajo ratificados por el congreso de Colombia forman parte del ordenamiento jurídico interno y son de obligatorio cumplimiento. El artículo 19 del Código laboral (Codigo Laboral Colombiano, 2017) dispone:

Normas de aplicación supletoria. Cuando no haya norma exactamente aplicable al caso controvertido, se aplican las que regulen casos o materias semejantes, los principios que se deriven de este código, la jurisprudencia, la costumbre o el uso, la doctrina, los convenios y recomendaciones adoptadas por la organización y las conferencias internacionales del trabajo, en cuanto no se opongan a las leyes sociales del país, los principios del derecho común que no sean contrarios a los del derecho del trabajo, todo dentro de un espíritu de equidad 
Efectivamente, según la actual Constitución, los convenios internacionales del trabajo debidamente ratificados "hacen parte de la legislación interna" (art. 53-4), o, incluso, pueden prevalecer en el ordenamiento, con jerarquía de normas constitucionales (arts. 93 y 94), o sea, como integrantes del bloque de la constitucionalidad. Por tanto, esos convenios y tratados ratificados, constituyen normas directamente aplicables en Colombia al caso controvertido, y no simples normas de aplicación supletoria, como quería el artículo 19 del Código Sustantivo del Trabajo: Los que versan sobre derechos humanos, Los relativos a libertad sindical y a la protección del derecho de sindicalización, los relativos a la protección del salario, sobre la "edad mínima de admisión en el empleo, sobre pueblos indígenas, sobre la "prohibición de las peores formas de trabajo infantil y acción inmediata para su eliminación". (Jaime Rodriguez Garreta, 2017). "Además es importante recalcar que los convenios que integran el bloque de constitucionalidad en sentido lato orientan la interpretación de la norma suprema, y que aquellos convenios que forman parte del bloque de constitucionalidad en sentido estricto prevalecen en el orden interno". (Jaime Rodriguez Garreta, 2017)

Lo anterior significa, ni más ni menos, que un convenio de la OIT ratificado por Colombia, se convierte en norma interna de naturaleza legal o constitucional, como si hubiera sido producida internamente. Se sigue de ello que, al momento de buscar la norma o normas reguladoras de un determinado caso, los jueces, funcionarios, abogados y demás operadores jurídicos, no deben limitar su indagación a las normas laborales de origen nacional (por ejemplo, las normas del CST, los actos administrativos pertinentes, etc.), sino que también deberán tener a la vista los convenios de la OIT que versen sobre la materia. Deberán aplicar la norma en la que se subsuma el caso, cualquiera sea su origen, observando los criterios de vigencia en el tiempo (antinomias) y de idoneidad, sin que sea admisible preferir la de origen nacional por el simple hecho de serlo (Carlos Ernesto Molina, 2005). En pocas palabras la existencia y reconocimiento en Colombia de los Derechos adquiridos, ciertos e indiscutibles del trabajador constituyen una condición beneficiosa enmarcada por la Ley, el respeto al ser humano productivo y la dignidad humana sin limitante alguna. 


\section{Instrumentos Jurídicos contenidos en la Legislación y en la Jurisprudencia Colombiana para la Protección de los Derechos Adquiridos, Ciertos e Indiscutibles de los Trabajadores}

Los instrumentos jurídicos que en nuestro país nos permiten dar protección a los derechos adquiridos, ciertos e indiscutibles parten de la correcta aplicación de los principios fundamentales del Derecho al trabajo entendiendo estos, como aquellos postulados que definen la norma laboral buscándole un sentido y dándole una firmeza jurídico laboral. Podemos dilucidar como un instrumento jurídico la posibilidad que tiene un trabajador de accionar el aparato judicial mediante la presentación de Demanda Ordinaria Laboral, demanda ejecutiva, tutelas, de igual forma la posibilidad que tiene un trabajador de presentar ante el empleador derechos de petición, o interponer recursos ante resoluciones de fondo de pensiones, etc., en aras de lograr la protección de sus derechos adquiridos, ciertos e indiscutibles.

Nuestro Código Laboral Colombiano teniendo en cuenta el tramite fijado para su realización, esto es su procedimiento, los clasifica en: Ordinarios y Especiales, el proceso ordinario laboral que es el que nos interesa, tiene dos modalidades: El de única y el de primera instancia. El proceso ordinario de única instancia esta reglado en los artículos 70 a 73 del C.P.T y de la S.S, se encuentra determinado por un factor objetivo (cuantía y naturaleza de la relación jurídica material). Según el artículo 9 de la Ley 712 el cual reformo el artículo 12 de C.P.T, son de única instancia los procesos que tengan una cuantía que no exceda los 10 salarios mínimos mensuales legales vigentes. Esta norma a su vez fue modificada por el artículo 46 de la Ley 1395 de 2010 en el sentido de fijar una suma equivalente a 20 salarios mínimos mensuales legales vigentes o menos para constituir un proceso de única instancia. (Fabian Vallejo Cabrera, 2016)

La demanda que da origen a un proceso ordinario de única instancia no tiene que ser escrita- aun cuando poder serlo- ya que el artículo 70 del código de la materia acepta que sea verbal. Formulada oralmente se levantará un acta donde consten los nombres, domicilios, direcciones del demandante y del demandado, lo que se demanda y los hechos que fundan la acción. En la misma diligencia el juez dispondrá la citación del demandado para que comparezca contestarla, previa notificación y traslado, en la audiencia que para el efecto se señale. En la única audiencia que conforma este procedimiento, el juez agotara lo dispuesto en el artículo 77 del CPT en este sentido si llegase a fallar 
la conciliación el funcionario judicial deberá resolver las excepciones previas y sanear las irregularidades del procedimiento que puedan originar nulidad o sentencia inhibitoria y, a continuación, fijara el litigio. Agotadas estas etapas decretará y recibirá pruebas. Clausurado el debate probatorio el juez debe fallar en el acto mediante sentencia que no es objeto de recurso alguno. De lo acaecido en la audiencia se debe levantar un acta que contendrá el nombre de las partes que intervienen, apoderados, testigos, auxiliares de la justicia, una relación de los documentos aportados, el auto que suspende la audiencia y la sentencia (Articulo 73 del C.P.L y de la S.S). (Fabian Vallejo Cabrera, 2016; Fabian Vallejo Cabrera, 2016)

El proceso ordinario de primera instancia lo regula el CPT y de la S.S en sus dos instancias en los artículos 74 a $85 \mathrm{~A}$. Al igual que el de única instancia está determinado por la cuantía de la pretensión y la naturaleza de la relación jurídica material. Tienen ese carácter los procesos de cuantía superior a 20 salarios mínimos mensuales legales vigentes según el artículo 46 de la Ley 1395 de 2010. (Fabian Vallejo Cabrera, 2016). Los procesos especiales constituyen en este orden de ideas, la excepción por cuanto, para que existan, el legislador debe haberlos expresamente establecido tal y como sucede con los procesos judiciales de fuero sindical ( Art 113 y s.s ), el ejecutivo (arts 100 al 111), el sumario de disolución, liquidación y cancelación de la inscripción en el registro sindical (art.56 de la Ley 50/90) y el extrajudicial de arbitramento (art,130 al 143), pues para cada uno de ellos la Ley procesal laboral tiene establecido un trámite propio y diferente. (Fabian Vallejo Cabrera, 2016). Los procesos judiciales en el ámbito laboral que nos atañe están ampliamente orientados por los Jueces laborales quienes deben dirigir el proceso dentro de un contexto absolutamente legal aplicando los principios de celeridad, transparencia, objetividad y sana critica entre otros.

El Código General del Proceso en el Artículo 42 dispone: deberes del juez. Son deberes del juez: 

medidas conducentes para impedir la paralización y dilación del proceso y procurar la mayor economía procesal.

2. Hacer efectiva la igualdad de las partes en el proceso, usando los poderes que este código le otorga.

3. Prevenir, remediar, sancionar o denunciar por los medios que este código consagra, los actos contrarios a la dignidad de la justicia, lealtad, probidad y buena fe que deben observarse en el proceso, lo mismo que toda tentativa de fraude procesal.

4. Emplear los poderes que este código le concede en materia de pruebas de oficio para verificar los hechos alegados por las partes.

5. Adoptar las medidas autorizadas en este código para sanear los vicios de procedimiento o precaverlos, integrar el litisconsorcio necesario e interpretar la demanda de manera que permita decidir el fondo del asunto. Esta interpretación debe respetar el derecho de contradicción y el principio de congruencia.

6. Decidir, aunque no haya ley exactamente aplicable al caso controvertido, o aquella sea oscura o incompleta, para lo cual aplicará las leyes que regulen situaciones o materias semejantes, y en su defecto la doctrina constitucional, la jurisprudencia, la costumbre y los principios generales del derecho sustancial y procesal.

7. Motivar la sentencia y las demás providencias, salvo los autos de mero trámite. La sustentación de las providencias deberá también tener en cuenta lo previsto en el artículo 7 sobre doctrina probable.

8. Dictar las providencias dentro de los términos legales, fijar las audiencias y diligencias en la oportunidad legal y asistir a ellas.

9. Guardar reserva sobre las decisiones que deban dictarse en los procesos. El mismo deber rige para los empleados judiciales.

10. Presidir el reparto de los asuntos cuando corresponda.

11. Verificar con el secretario las cuestiones relativas al proceso y abstenerse de solicitarle por auto informe sobre hechos que consten en el expediente.

12. Realizar el control de legalidad de la actuación procesal una vez agotada cada etapa del proceso

13. Usar la toga en las audiencias.

14. Usar el Plan de Justicia Digital cuando se encuentre implementado en su despacho judicial.

15. Los demás que se consagren en la ley.

Imagen 1. Deberes del juez

Creación de autor, fuente: Código General del Proceso en el Artículo 42, Año 2018

El Código General del Proceso en el Artículo 43 dispone: Poderes de Ordenación e instrucción: 


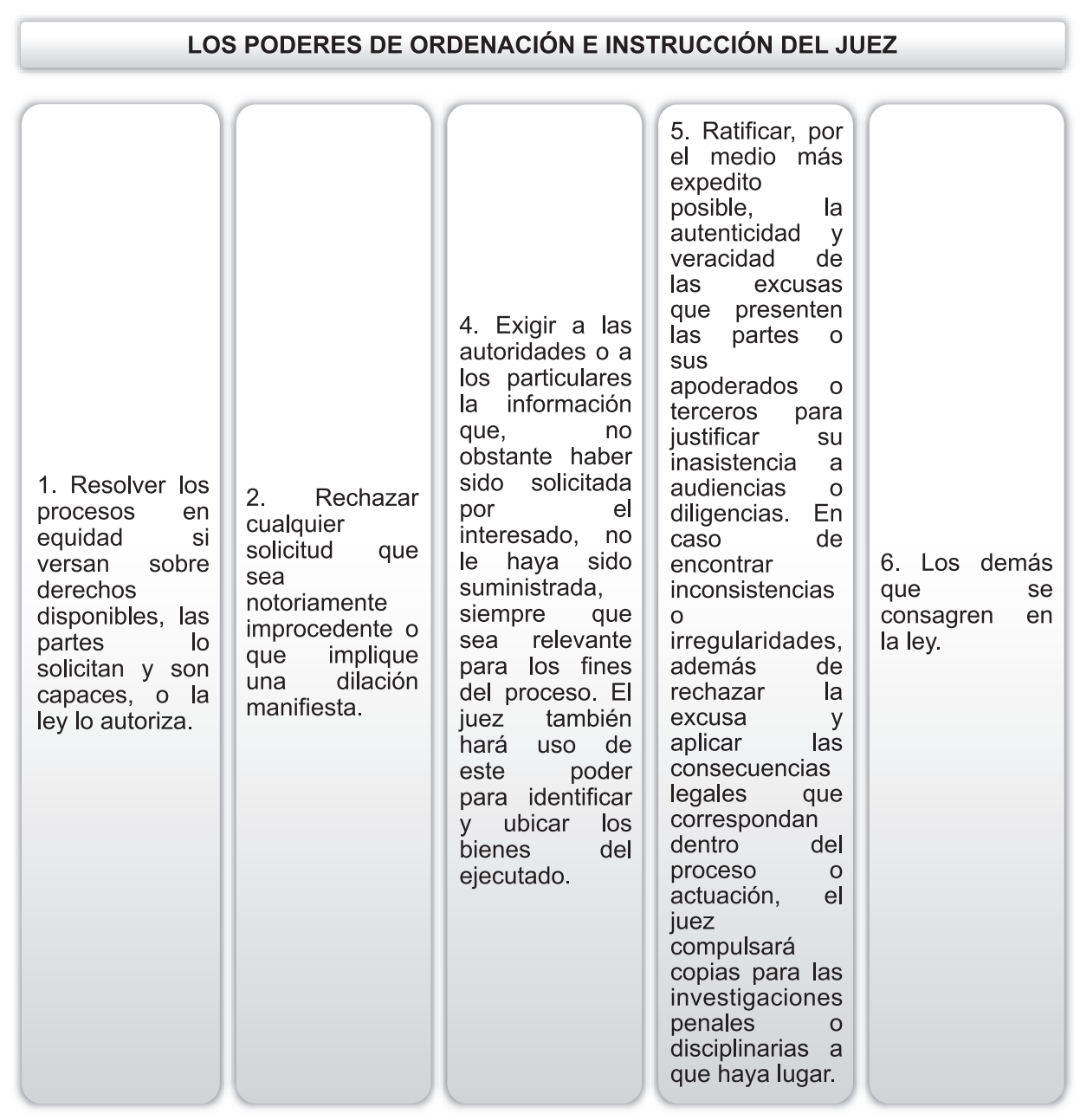

Imagen 2: Poderes de Ordenación e instrucción

Fuente: Creación de autor, fuente: Código General del Proceso en el Artículo 43, Año 2018

En este orden de ideas el juez jamás debe convertirse en un dictador o tirano dentro del proceso sino en un garante de los Derechos adquiridos ciertos e indiscutibles de los trabajadores que acuden a instancias judiciales enmarcados en el contexto legal e irrenunciable de sus derechos. Además de los jueces laborales, el Ministerio de trabajo mediante sus servidores públicos llamados inspectores de trabajo y las direcciones territoriales, también debe dar protección a los derechos adquiridos, ciertos e indiscutibles de los trabajadores en Colombia, 
de igual forma el Gobierno Nacional mediante la implementación y seguimiento de políticas públicas que den protección al trabajo en condiciones dignas y justas para dar cumplimiento a lo preceptuado en el artículo Primero de nuestra Carta Magna.

Artículo 1. Colombia es un Estado social de derecho, organizado en forma de República unitaria, descentralizada, con autonomía de sus entidades territoriales, democrática, participativa y pluralista, fundada en el respeto de la dignidad humana, en el trabajo y la solidaridad de las personas que la integran y en la prevalencia del interés general.

\section{Análisis Estadístico de Consultorio Jurídico de CECAR En Materia Laboral Año 2017}

De conformidad con el Acuerdo No 30 del 03 de diciembre de 2014, la Corporación Universitaria del Caribe - CECAR, modificó el Reglamento Interno de Consultorio Jurídico de la Facultad de Derecho y Ciencias Políticas de CECAR, y en sus consideraciones estableció que:

Los Consultorios Jurídicos deben garantizar a la sociedad la prestación del servicio social jurídico en condiciones éticas, eficaces y eficientes, dentro de los más elevados parámetros de calidad y excelencia académica, lo cual requiere establecer los lineamientos generales para la prestación del servicio de asistencia jurídica en forma gratuita a las personas de escasos recursos económicos. (Corporación Universitaria del Caribe , 2014).

Bajo este entendido, desde este centro de proyección social del programa de Derecho, cumpliendo lo establecido en la norma interna en disposiciones legales del orden nacional, desde el Consultorio Jurídico se prestan asesorías y acompañamiento judicial y extrajudicial a población vulnerable, que no puede acceder los servicios profesionales de un abogado.

En la gráfica siguiente, se muestran las estadísticas manejadas por este centro de prácticas de procesos judiciales iniciados durante la vigencia académica 2017: 
Estadísticas Consultorio Jurídico 2017

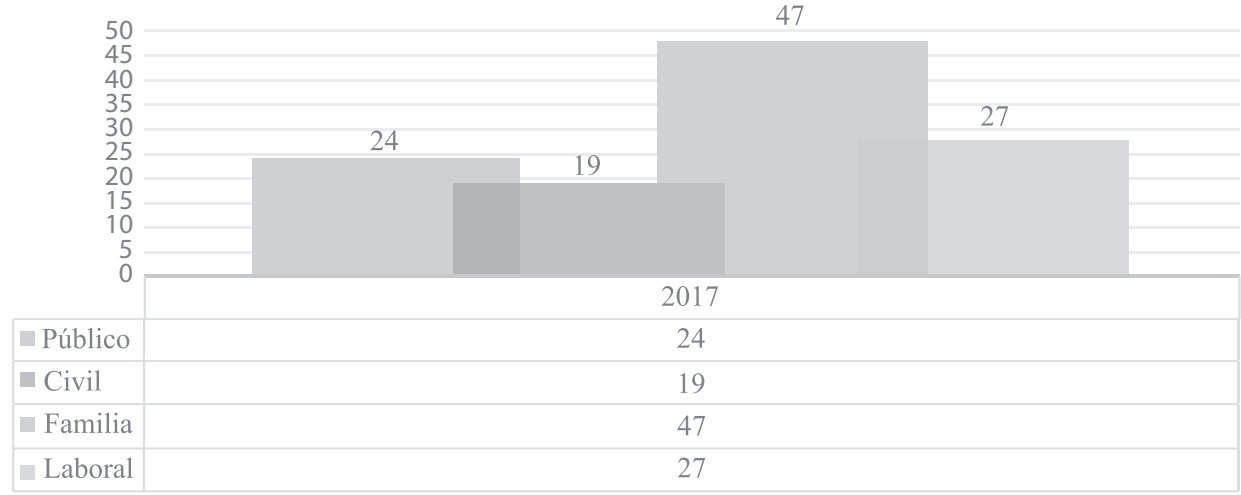

Gráfica 1. Estadísticas Consultorio Jurídico 2017

Fuente: Creación de autor. Fuente: Informe de Monitoria, Consultorio Jurídico CECAR, año 2017

De acuerdo con el gráfico anterior, observamos que el área que más flujo de atención tiene es el área de Derecho de Familia, compuesto por los procesos de alimentos y ejecutivos de alimentos. Sin embargo, el área de Derecho laboral, si bien no tiene un alto número de procesos activos, frente al área de familia, los veintisiete (27) procesos laborales adelantados durante el 2017, en su mayoría derivado de las conciliaciones fallidas ante el Ministerio del Trabajo - Territorial Sucre, como se evidencia en los expedientes, indican un índice de tramites considerable, denotada la complejidad de estos tipos de procesos en donde se busca la declaratoria y reconocimiento de la relación laboral o el pago de acreencias laborales.

Ahora bien, tal como se muestra en la gráfica subsiguiente, de los veintisiete (27) procesos laborales adelantados en 2017, veinticuatro correspondieron a procesos ordinarios laborales y tan solo tres (3) a procesos ejecutivos laborales: 


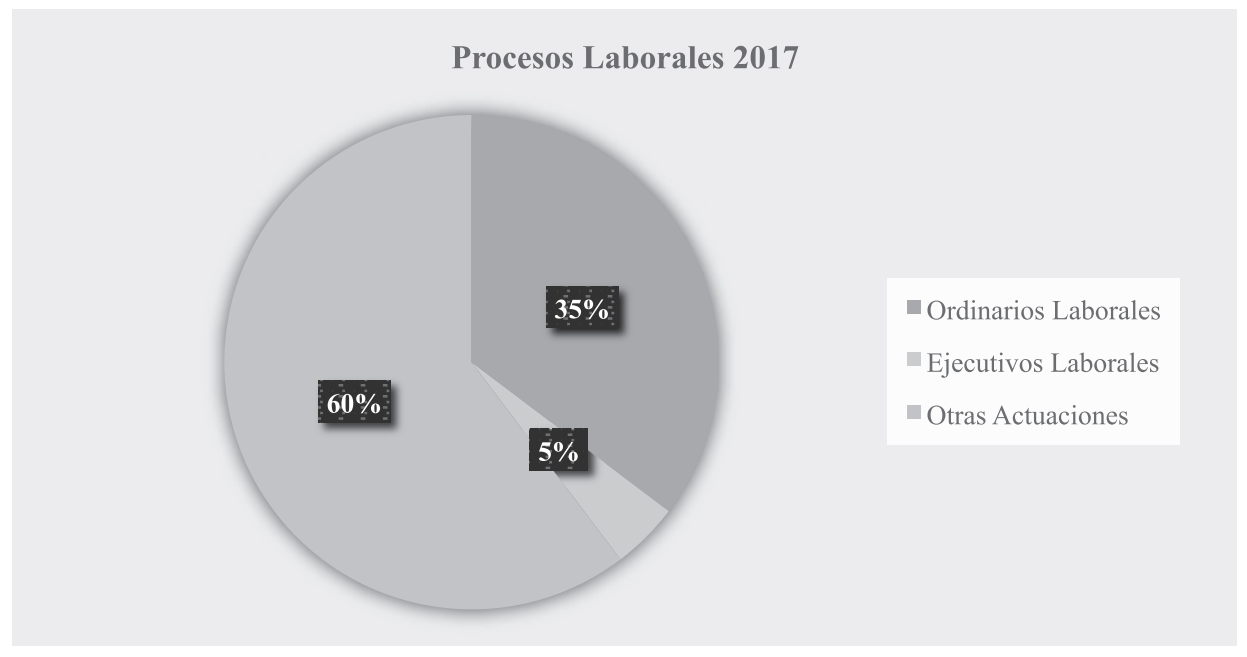

Gráfica 2. Procesos Laborales 2017

Fuente: Creación de autor. Fuente: Informe de monitoria, Consultorio Jurídico CECAR. Año 2017

Existe en la anterior gráfica un porcentaje del 60\% de actuaciones distintas a procesos ordinarios y ejecutivos laborales, que contienen las estadísticas de solicitudes, derechos de petición a entidades públicas y privadas en materia de pensiones, realización de liquidación de acreencias laborales o a otras actuaciones no judiciales en materia laboral. Pero otro hecho que resulta relevante es la diferencia sustancial entre los procesos ordinarios laborales y los procesos ejecutivos, constituyéndose los primeros en la herramienta judicial más desarrollada durante el año 2017, lo que indica, que la mayoría de asuntos tramitados en Consultorio Jurídico obedecen principalmente a la necesidad de declarar la existencia de un contrato de trabajo y los extremos de la relación laboral, debido a la poca utilización de contrato laboral escrito al momento de emplear a personas en Sincelejo, lo que requiere, por supuesto de un análisis mucho más profundo por parte de los observatorios laborales presentes en el municipio y por parte del mismo Ministerio del Trabajo.

Por otro lado, no solamente se realiza propiamente el diligenciamiento procesal de las causas de los usuarios de consultorio jurídico, ya que los asesores de esta área se encargan del acompañamiento, asesoría y supervisión de las actuaciones adelantadas no solo por los estudiantes del programa de Derecho adscritos al centro de prácticas, sino a los monitores judicantes de Consultorio Jurídico, quienes también adelantan procesos judiciales en ejercicio de la función social de la 
abogacía, y como requisito habilitante de su práctica jurídica. Así, pues, para el 2017, las siguientes fueron las estadísticas en materia de asesoría y acompañamiento por parte de los asesores de área:

\section{ASESORÍAS Y ACOMPAÑAMIENTO}

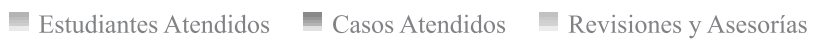

113

48

48

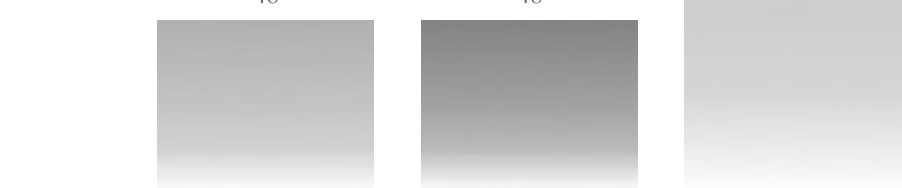

2017

Gráfica 3. Asesorías y Acompañamiento 2017

Fuente: Creación de autor. Fuente: Informe de Monitoria Consultorio Jurídico CECAR, año 2017

El gráfico precedente contiene el ejercicio de asesoría docente durante el año 2017, que incluyen las revisiones de los procesos que vienen siendo adelantados de vigencias anteriores, por lo que existe diferencia en el número de procesos adelantados durante el año y el número de procesos asesorados por los docentes encargados del área. No obstante, dicho gráfico muestra la importante labor desarrollada por estos profesionales del derecho que mediante la vinculación como docentes de tiempo completo adscritos al Consultorio Jurídico y Centro de Conciliación, acompañan el camino formativo y profesional de estudiantes y egresados del programa de Derecho de CECAR, evidenciando que el impacto no solamente se realiza en los despachos judiciales sino en el proceso formativo de los abogados de esta Corporación, materializando de esta manera la impronta que caracteriza a esta casa de estudios: Formación con Responsabilidad Social.

\section{Análisis de los resultados}

Al realizar el análisis estadístico del Consultorio Jurídico de CECAR se evidenció que el área de derecho laboral, asesorada por una abogada docente, especialista en Derecho laboral y seguridad social asesora de 
tiempo completo es la segunda área en orden descendiente, en número de procesos adelantados durante el 2017. De la misma manera, se evidenció la amplia utilización proceso ordinario laboral en única instancia, sobre otras actuaciones judiciales, lo cual es un indicador de la informalidad en la vinculación de empleados, de la población que acude a los servicios de este centro de proyección social. Además, que, si bien no son actuaciones judiciales, tanto estudiantes como monitores del Consultorio Jurídico, conocen de asuntos y consultas en materia laboral, y que se abordan a través de documentos no judiciales.

\section{Conclusión}

Al finalizar este estudio se ha logrado identificar que el aporte de consultorio jurídico de CECAR a la protección de los Derechos adquiridos, ciertos e indiscutibles de los trabajadores en Sincelejo durante el año 2017 es bastante significativo en asesoría y/o acompañamiento jurídico, predominando la presentación, seguimiento y finalización de Demandas Ordinaria Laborales de Única Instancia ante Juez de Pequeñas causas laborales de la ciudad de Sincelejo, en cuantía que no supera los 20 Salarios Mínimos Legales vigentes, de otro lado se resalta la presentación, seguimiento y finalización de Demandas Ejecutiva laboral, antes el juzgado mencionado, aunque en menor proporción, además la elaboración de documentos afines como los son derechos de petición, acciones de tutela, liquidaciones de acreencias laborales, recursos ante negación de solicitud pensional, asesoría regímenes especiales y demás documentos no judiciales.

Constituye lo anterior un ahorro económico para el usuario y para su núcleo familiar por cuanto es un servicio de asesoría jurídico laboral gratuito brindado por Consultorio Jurídico de CECAR, el usuario solo está obligado a asumir los gastos que se generen como fotocopias y/o notificaciones.

De otro lado cuando un usuario sale satisfecho de las oficinas de Consultorio Jurídico de CECAR con la asesoría jurídica brindada y/o el acompañamiento jurídico en el caso laboral, CECAR mediante la proyección social contribuye con la protección de los derechos adquiridos, ciertos e indiscutibles de los trabajadores y ex trabajadores que acuden a consultorio jurídico muchas veces agobiados por la situación laboral que padecen y encuentran una mano amiga que lo direcciona a la obtención de la protección de sus Derechos Laborales generalmente desconocidos y/o vulnerados por el empleador, contribuyendo también de esta 
manera con la tranquilidad emocional de estos usuarios destacando que la asesoría jurídica brindada es óptima enmarcada en el ordenamiento jurídico vigente.

\section{Referencias}

Carlos Ernesto Molina. (1 de septiembre de 2005). Analisis de Sentencia C 401/2005. Articulo. Bogota, Bogota, cOLOMBIA .

Codigo Laboral Colombiano Legis. (2017). Primero. Bogota: Legis.

Constituciion Politica De Colombia. (1991). Constitucion Politica De Colombia. Bogota: Legis.

Corporación Universitaria del Caribe . (3 de Diciembre de 2014). Reglamento Consultorio Jurídico. Obtenido de https://cecar.edu.co/normas-internas

Cruz, J. (2017). Compesio Del Derecho De Trabajo. Bogota: Tecnos. De la irrectroactividad de las leyes. (s.f.).

Derecho Laboral Colombiano relaciones individuales. (2014). Irrenunciabilidad del derecho. Bogota: Legis.

Fabian Vallejo Cabrera. (2016). Derecho Procesal del trabajo y de la seguridad social. Medellin: Libreria juridica Sanchez R ltda.

Figueroa, G. G. (2016). Principios fundamentales del derecho al trabajo. bogota: Leyer.

Gerencie.Com. (S.F.).

Gonzalez Charry Guillerom . (2016). Derecho Laboral Individual . Bogota : leyer.

Jaime Rodriguez Garreta. (2017). Guia Relaciones Laborales y Prestacionales. Bogota: Ediciones Doctrina y Ley LTDA.

Jesus Cruz Villalon . (2017). Compedio Del Derecho De Trabajo . Madrid: tecno.

Jesus Cruz Villalon. (2017). Compedio De Derecho Del Trabajo. Bogota: Tecno(Grupo Anaya, S.A). 